\title{
Ethical limits to the intrusiveness of online advertising formats: A critical review of Better Ads Standards
}

\author{
Daniel Belanche \\ Department of Marketing and Market Research, Faculty of Economy and Business, \\ University of Zaragoza (Spain)
}

This manuscript is a previous shorter version of the research, the final version was published at the Journal of Marketing Communications:

https://doi.org/10.1080/13527266.2018.1562485

\begin{abstract}
This article argues that advertising ethics, traditionally focused on ad contents and vulnerable audiences, should be also applied to ad format intrusiveness. The increasingly appearance of highly intrusive advertising formats resulted in an extraordinarily growth of ad blocking systems. To fight the economic costs of the ad blocker phenomenon, the most relevant agents of the industry have created a never seen Coalition for Better Ads including marketers, publishers and agencies worldwide. This article analyses the experiments carried out by the Coalition to create Better Ads Standards establishing the limits of ad format intrusiveness to be implemented worldwide by means of self-regulation. Based on classical and current approaches to advertising ethics, this work explains that highly annoying ads should not only be banned for practical reasons but for overpassing ethical limits in terms of respect for the persuadee, equity of the persuasive appeal and social responsibility for the common good. A basic exploratory replication study is presented to stimulate further research on the ethical limits of intrusive advertising. Establishing which ad formats are allowed to continue and which ones should gradually disappear is such a relevant process for many stakeholders that it requires further discussion by consumers and scholars.
\end{abstract}

Keywords: online advertising, advertising formats, advertising ethics, intrusiveness, self-regulation, standards 


\section{Introduction}

One day, a colleague tells you to check online news that could affect your job. However, before entering the webpage you have to watch a 10 seconds video ad about the financial products of a bank. After some seconds looking at the countdown timer and missing a skip button, you start reading the content but a red and yellow flashing animated ad distract your attention to remind you a 30\% discount in a department store. Finally, when trying to read the complete text, a scrollover ad presenting some other product with dog images follow your movement as you scroll down the page.

Many readers probably feel identified with this exasperating advertising experience and would admit that this description is not exaggerated but frequent in online media. This kind of communication management could be described as irresponsible, and may damage the interrelation between consumers, publishers and advertisers (Ha and McCann 2008). Because an irresponsible use of communication sometimes results in dissatisfying experiences (Kitchen and Sheth 2016; Lim, Chock, and Golan 2018), consumers try to avoid intrusive ads by all means (Kelly, Kerr, Drennan 2010; Belanche, Flavián, and Pérez-Rueda 2017b). Despite such kind of catastrophic communication interaction, little has been done in the last decades to enhance the online advertising experience or at least mitigate the problems derived of a highly dissatisfying or annoying experience.

In the absence of a global government determining a set of minimum standards of online advertising formats, the typical agents of the advertising industry (i.e. advertisers, publishers, technology platforms), have created an alliance to avoid the dramatic economic consequences of the ad blocking phenomenon, which is experiencing a tremendous growth in the last years (Tudoran 2018). More precisely, this Coalition for Better Ads has the mandate to establish some ad standards that identify inappropriate ad formats in terms of consumer annoyance to be discouraged in the market by means of self-regulation. Like previous self-regulation initiatives (Shaver 2003; Feenstra and González-Esteban 2017), it is expected that these standards would be widely applied across advertising agents in the next years; meaning that this issue would be affecting all stakeholders in the online advertising environment.

To advance in this interesting issue, this research proposes that the intrusiveness of advertising formats should not overpass some limits for practical and ethical reasons. Indeed, establishing the limits of advertising annoyance should be considered a challenging ethical issue which is intrinsically linked to its practical consequences, and that need to be deeply explored by academics and practitioners. The proliferation of different and multifaceted online advertising formats, ad blocking systems, and other initiatives establishing ad format standards in the last years, warns that an urgent scientific development of this field is required (Redondo and Aznar, 2018).

\section{Literature Review: New Challenges of Advertising Ethics in the Digital Age}

\section{Teleological and deontological classical approaches}

Within the functional areas of a business, adverting is rated the lowest in terms of ethical standards, being historically blamed for many unethical practices (Keith et al. 2003); advertising ethics has been considered as an oxymoron (James, Pratt, and Smith 1994; Beltramini, 2003).

From a moral approach, advertising ethics is defined as "what is right or good in the conduct of the advertising function [...] and what ought to be done, not just whit what legally must be done” (Cunningham 1999, 500). To identify “what ought to be done”, normative ethics search 
for normal or authoritative moral standards that establish the limits between appropriate and inappropriate practices (James, Pratt, and Smith 1994), and that can be found by teleological and deontological approaches.

For the teleological school, the integrity of an ad is determined solely by its consequences, such as the harm on the consumer (James, Pratt, and Smith 1994). Although this teleological view continues being used as a method to identify unethical ads, this approach has been widely criticized because for being consequentialist, while the cause-consequence is very often hard to prove, and for ignoring the intrinsic moral worth of the ad by itself (Lee and Nguyen 2014).

In turn, the deontological school holds that the morality of an ad depends on its intrinsic nature or motives, and that advertising have to follow some moral rules or principles (James, Pratt, and Smith 1994). Thus, according to deontological ethics, the advertiser is bound by duty and moral soundness based on a professional practice of advertising (Lee and Nguyen 2014), and that is reflected in professional codes and standards of ethics usually specified by the government, the industry and the public (James, Pratt, and Smith 1994).

\section{Current approaches to advertising ethics}

Previous research and reports by national entities in defence of consumer rights continue advancing in the purpose to lessen unethical practices in advertising. In the last decades, a great amount of studies dealing with advertising ethics have identified that unethical practices mostly refer to the use of controversial contents (e.g. Rinallo et al. 2013). For instance, Moraes and Michaelidou (2017) identify ethical issues in advertising related to matters of deception, representation, targeting of vulnerable populations, the morality of advertising and advertising professionals, advertising of contentious products, advertising as persuasive ideology, and controversial advertising (provocative or obscene).

A lower but significant stream of research and discussion has focused on unethical practices derived from addressing specific targeted audiences, with a special focus on children. This is because of children vulnerability associated to their difficulties to understand the difference between the programed content and advertising with persuasive intentions (Haefner 1991; Daems, De Pelsmacker, and Moons 2018). However, many people with poor advertising literacy should be considered vulnerable too, as far as they have difficulties to recognize advertising or to understand the persuasive intentions behind ads (Daems, De Pelsmacker, and Moons 2018). The lack of ability to identify commercial concepts is not only determined by demographic or psychological traits but to many other situational elements such as the subtlety of the persuasive message, the similarity between the ad and the context in which it is embedded and the presence of any kind of cue to announce that the consumer is being exposed to a commercial message (Daems, De Pelsmacker, and Moons 2018).

Indeed, the use and abuse of audience vulnerability is a particularly awkward problem in the current online context. Plenty of different contents, platforms, and advertising formats coexist in a continuously evolving digital environment where even heavy users are barely qualified to deal with such stimuli clutter. As an example, "stealth marketing" is a term that describes advertisers' payment for the inclusion of their products into editorial content, reducing consumers' capability to distinguish advertising from publicity (Rinallo et al. 2013; Sabri 2017). Also new formats of unwanted ads appear continuously during users' navigation obstructing the normal use of smartphones and other devices. 


\section{Advertising format and intrusiveness: a research gap}

Taking into account all previous considerations, advertising format emerges as an interesting, underdeveloped, and often ignored issue in advertising ethics, not specifically analysed by scholars or leading advertising textbooks (Drumwright and Murphy 2009). In the absence of a core body of knowledge dealing with advertising format and ethics, previous literature suggests some insights to advance on this research gap.

The TARES test (Baker and Marthinson 2001) is a conceptual model of advertising guidelines which establishes five principles for ethical persuasion: (1) Trustfulness of the message, (2) Authenticity of the persuader, (3) Respect for the persuadee, (4) Equity of the persuasive appeal, and (5) Social Responsibility of the common good. Looking carefully to the checklist of aspects dealing with each of the five principles, it may be argued that intrusive advertising formats are not directly linked with the trustfulness of the message or the authenticity of the persuader, but with the rest of principles. According to the TARES categorization, Table 1 explains why highly annoying ads should be frequently considered unethical when they do not treat persuades with respect, threats the equity that should be assumed in persuasive communications, or harms the social responsibility of advertising in society. Every highly annoying ad format does not necessarily break all the ethical issues described in this list. However, most unethical practices result from business models based on online advertising, where publishers obtain incomes per each view or click, with little concern about users' best interest or even about the effectiveness of such persuasive communication.

Critics about the unethicality of advertising formats have already developed some of the concerns exposed in the TARES test. A principal stream of research is devoted to the use of advertising formats which diminish consumers' ability to identify or being warned against persuasive advertising. An alarming example of this unethical and sometimes forbidden practice is the use of subliminal stimuli, widely covered by research on psychology and advertising some decades ago (Key 1973; Moore 1982). From an updated approach, online practices such as the already mentioned "stealth marketing" which mask advertising with other contents to make it unrecognizable or difficult to process would be an unethical practice that take advantage of consumer vulnerability. From a complementary perspective, previous research has also identified that new advertising formats affect consumers' interaction with advertising (e.g. need to learn how to skip an ad, Belanche, Flavián, and Pérez-Rueda 2017b) and message ethicality processing (e.g. different in video than in sill images, Meader et al. 2015).

A second approach to deal with ethics in advertising formats focus on the invasiveness and disturbance caused by some advertising formats. In this sense, advertising intrusiveness emerges as a consumers' psychological reaction against advertising that interfere with their ongoing cognitive processes (Li, Edwards, and Lee 2002). Generally, research has studied intrusiveness with minimal concern on its ethics, usually considering annoyance just as an element damaging advertising effectiveness (Van Doorn and Hoekstra 2013; Goodrich, Schiller, and Galletta 2015). A noteworthy exception of research analysing advertising intrusiveness refers to studies on billboard advertising causing distraction among drivers, but they focus on accident prevention rather than on the ethicality of the communication (Ady, 1967; Crundall, Van Loon, and Underwood 2006). 


\section{Table 1. Frequent unethical aspects present in highly intrusive online advertising formats based on TARES test for ethical persuasion}

\begin{tabular}{|c|c|c|}
\hline \multirow{7}{*}{$\begin{array}{l}\text { Respect for } \\
\text { the persuadee }\end{array}$} & $\begin{array}{l}\text { Reflection } \\
\text { capacity }\end{array}$ & $\begin{array}{l}\text { The ad does not facilitate persuadees' capacity to reflect } \\
\text { and to make responsible choices } \\
\text { The ad does not contribute to the understanding, } \\
\text { consideration, reflection and valid reasoning; or lessen } \\
\text { informed, free-will assent and consent }\end{array}$ \\
\hline & & $\begin{array}{l}\text { The ad could be more respectful and responsible to the } \\
\text { people to be persuaded }\end{array}$ \\
\hline & $\begin{array}{l}\text { Respect as a } \\
\text { human being }\end{array}$ & $\begin{array}{l}\text { The dignity, interests and well-being of persuadees are not } \\
\text { into consideration }\end{array}$ \\
\hline & & $\begin{array}{l}\text { The ad promote raw self-interest at the unfair expense or to } \\
\text { the detriment of persuadees (e.g. income per view) }\end{array}$ \\
\hline & & $\begin{array}{l}\text { The quality of the information is inadequate for the } \\
\text { information needs of the persuadee }\end{array}$ \\
\hline & $\begin{array}{l}\text { Information } \\
\text { quality }\end{array}$ & $\begin{array}{l}\text { The message does not facilitate the persuadees’ capacity to } \\
\text { act well (i.e. to choose, speak) }\end{array}$ \\
\hline & & $\begin{array}{l}\text { The ad does not appeal to the receiver higher inclinations } \\
\text { and basic goodness but pander, exploit or appeal to their } \\
\text { lower basic inclinations (e.g. flashing ads) }\end{array}$ \\
\hline \multirow{4}{*}{$\begin{array}{l}\text { Equity of the } \\
\text { persuasive } \\
\text { appeal }\end{array}$} & & $\begin{array}{c}\text { The context, nature or execution of the ad presentation is } \\
\text { unfair (e.g. obstructing other contents) }\end{array}$ \\
\hline & $\begin{array}{c}\text { Context } \\
\text { unfairness }\end{array}$ & $\begin{array}{l}\text { The ad format/context take unfair advantage of a power } \\
\text { differential over the persuadee }\end{array}$ \\
\hline & & $\begin{array}{l}\text { The ad experience would not be perceived as fair, just, } \\
\text { ethical or appropriate if applied to the sender or people } \\
\text { he/she cares about }\end{array}$ \\
\hline & $\begin{array}{l}\text { Vulnerability } \\
\text { and ad } \\
\text { understanding }\end{array}$ & $\begin{array}{c}\text { The power of persuasion is used not fairly or justly, ads do } \\
\text { not consider the person or circumstances involved in the } \\
\text { persuasion } \\
\text { The ad targets potential vulnerable audiences or makes } \\
\text { claims outside of their ability to understand the context or } \\
\text { the underlying claims }\end{array}$ \\
\hline \multirow{3}{*}{$\begin{array}{l}\text { Social } \\
\text { Responsibility } \\
\text { for the } \\
\text { common good }\end{array}$} & Potential & $\begin{array}{l}\text { The persuasive commutation does not clearly help to } \\
\text { elucidate issues, neither dispel confusion or ignorance }\end{array}$ \\
\hline & $\begin{array}{l}\text { harm to } \\
\text { individuals } \\
\text { and to } \\
\text { common } \\
\quad \text { good }\end{array}$ & $\begin{array}{l}\text { The advertising action is not responsible to individuals or to } \\
\text { the public interest and has a potential negative impact on } \\
\text { the common good (e.g. ad related irritation) } \\
\text { The ad formats deplete public trust and focuses on an } \\
\text { individual approach which avoids understanding and } \\
\text { cooperation among constituent groups of society }\end{array}$ \\
\hline & $\begin{array}{l}\text { Use of } \\
\text { alternatives }\end{array}$ & $\begin{array}{c}\text { The replacement of these formats by alternative ones would } \\
\text { alleviate some of the unnecessary harm to people or to } \\
\text { society }\end{array}$ \\
\hline
\end{tabular}


Frequently, both the kind of online formats and the so abundant exposition to ads results in ad clutter (e.g. flashing animations, webpages where most of the screen is full of ads, etc.). Indeed, the online interactive environment is characterized by higher perceptions of invasiveness and calls to action (Belanche, Flavián, and Pérez-Rueda 2017a), compared to traditional mass media with a more informative or educative focus. The intrusiveness of online advertising formats has been proved to cause feelings of irritation, interruption, disturbance and avoidance ( $\mathrm{Li}$, Edwards, and Lee 2002; Edwards, Li and Lee 2002), which consequently is assumed to harm consumers' welfare. Exposing consumers to highly disturbing advertising formats have been detrimental in terms of consumers' lack of control, physiological stress, violation of freedom, negative affect (Tudoran 2018); as well as for firms, such as negative attitudes towards the advertised product, lower loyalty to the website, or higher economic costs (Goldstein et al. 2014; McCoy et al. 2008). Most of the digital advertising presented when entering to a website could be also described as "irrational advertising" developed against users' happiness or audience's autonomy, and considering the audience as a mere mean towards a commercial operation (Villarán 2015), with minimal concern to consumer interests (Kitchen 2017). This description proposes that online advertising is far from the deontological approach of "treat customers with respect, concern, and honesty, the way you yourself would want to be treated" (Robin and Reindenbach 1987, 55).

In any case, even from a deontological approach, it is very difficult to establish the ethical limits to distinguish appropriate for inappropriate advertising formats. Thus, the ad blocking phenomenon has emerged as a way to, at least partially, solve the problem of dealing with highly intrusive ads.

\section{The ad blocking phenomenon}

The installation of an ad blocking software is probably the simplest way to reduce user exposure to online advertising, and specifically to those ad formats that result highly intrusive. The scare emerging research on users' motivations to install ad blockers identified perceptions of intrusiveness and obtrusiveness, together with other hidden performance cost such as the use of data memory in smartphones, as their main determinants (Tudoran 2018; Redondo and Aznar 2018). Current statistics about ad blocking installation increase the awareness and relevance of such phenomenon. During the two-year period 2015-2016 ad blocking installation grew a 45\% in desktop computers and a 162\% in mobile phones globally (Page Fair 2017). This means a penetration rate around 20\% among users of North America and Western Europe (Page Fair 2017), where ad blockers intervene in one fifth of user experiences with a dreadful impact for the online advertising industry.

Nevertheless, ad blockers are not charitable foundations but just another agent in the online advertising ecosystem with their own business models. Indeed, some ad blockers work in exchange of users' payment or subscription; others charge fees to some advertisers in order to not to block their ads (e.g. Google, Microsoft or Amazon made some payments to AdBlock Plus to enter in its whitelist; Cookson 2015); and paradoxically, some ad blockers replace ads with other ads or work in exchange or ad watching. On this threatening context that seems to be ruled by the law of the jungle, some publishers opted for anti-ad blocking strategies and developed systems that block ad blockers, engaging in a technological race to cash users' subscriptions or advertising revenues (Redondo and Aznar 2018).

Like in offline marketing, online markets should be more regulated and governments should play a more relevant role on these communication processes (Kitchen and Sheth 2016). Nevertheless, in the absence of a global government regulating the online advertising 
environment, somebody else needs to lead the process to put order on this chaos and to establish the limits of highly annoying advertising.

\section{A Review of the Process to Determine Advertising Format Standards}

\section{The Coalition for Better Ads}

In 2016, a group of giants including Google, Facebook, Microsoft, P\&G, Unilever, Thomson Reuters, the World Federation of Advertisers (WFA) and the Interactive Advertising Bureau (IAB) formed an alliance to settle global standards for online advertising. With the purpose of being inclusive and in order to reach a wide global agreement, the Coalition for Better Ads grouped 35 members and 81 affiliates from all around the world. This never seen before alliance groups different kind of agents in the advertising industry, including also publishers and competitors.

The goal of the Coalition is to "leverage consumer insights and cross-industry expertise to develop and implement new global standards for online advertising that address consumer expectations" (Coalition for Better Ads 2017). The alliance frequently appeals to the enhancement of the customer experience as the leading force of its actions. Nevertheless, reading between the lines, it may be understood that the purpose of this alliance is to fight ad blockers by applying a similar strategy, that is, discouraging bad practices in the online advertising industry by means of self-regulation.

The alliance has the mandate to create an instrument for self-regulation in the industry and its success will depend on its application. Thus, the members of the Coalition are inviting to publishers to adopt such standards. Because of dominant firms are assuming the leadership in the spread of these self-regulating practices widely, it could be expected that the remaining agents should also adopt it in the medium term.

\section{The Initial Better Ads Standards: a research review}

In 2017, the Coalition for Better Ads released the results of a research carried out during the last year to determine a set of acceptable and unacceptable ad experiences. Ad web experiences referred to more than 50 ad formats (e.g. sticky ad on bottom, autoplayed video ad with/without sound, prestitial with/without countdown) in a specific device (either desktop or mobile) and context (article reading task). According to the general description of the research, results were based on surveys to more than 25,000 Internet users in North America and Europe.

The research was mainly structured in three studies, each of them considering both desktop and mobile web experiences. Although, compared to scientific research, reports are messy and do not always provide detailed information ${ }^{1}$, it can be observed that all the three studies present common characteristics. The three studies surveyed users in North America who were addressed online through Mechanical Turk (MTurk), with the exception of a second phase of a study in which participants were recruited from a non-disclosed vendor that emailed users registered in its system. In a kind of experimental design, all the users had the same task, that is, to read a 400 words article from a well reputed publisher adapted to the desktop or mobile web. The same three creatives (automotive, furniture and insurance) were used across studies. All the participants were exposed to a specific ad format depending on the condition (or no ad in the control condition).

\footnotetext{
${ }^{1}$ The Coalition did not provide additional information when contacted by the author.
} 
The research was designed in a constructive way, meaning that the findings of the earlier studies were the basis for the latter studies. The design of the subsequent studies advanced toward the final goal of making a list of unacceptable ads, which are those scoring higher in the rank of annoyance.

The first study included both a single-ad between-subject experiment and a three round multiad within-subject experiment (plus a no ad control condition). As a kind of scales' measurement (usually ranging from 1 "not at all" to 5 "very much"), this study asked about user's overall experience satisfaction, user's expectations, web performance, and evaluation of the experience as annoying, useful, trustworthy, visually pleasing, distracting, inappropriate and creepy. Sociodemographical information and overall attitude toward online advertising were also included in the questionnaire to a sample of 3,158 participants. As an initial study, results showed that ad format does not affect too much in terms of some of the variables such as visual pleasantness, and that the differences between formats in terms of overall experience were often minimal. However, some specific formats such as pop-ups are clearly perceived as negative experiences, whereas sticky ads are the most satisfactory experience after the no ads control group.

The second study was performed in two phases, involving 4,177 and 9,554 participants respectively. Although the measurement of variables remained, to favour the creation of a rank, each participant in this study was exposed to three different ad formats and had to select which one was the most and the least preferred. In the first phase, participants had to rank three ad experiences repeating this task several times. To capture subtle differences in the rank, at each step, participants had to assess ad experiences ranked closer together in the previous stages (there were 40 desktop and 37 mobile ad experiences). In the second phase, additional ad experiences were added and compared to ad experiences ranked in the first phase. Results indicated that annoyance and distraction measures highly affect rating differences because the rank is based on participant's selection of the most and least annoying ad experience between three. However, there are some outliers, suggesting that other metrics are relevant too. Results slightly differ between desktop and mobile experiences. The best ad experience on mobile are sticky ads placed at the bottom, whereas on desktop sticky ads placed at the bottom are more annoying, and the best ranked experiences are sticky ads placed at the top. The worst ad experiences on mobile are pop-up with countdown and single column ad of $50 \%$ density. In turn, the worst ad experiences on desktop are popup with or without countdown. Sticky experiences ranked worse on desktop than on mobile. However, in most cases experiences tested in both mobile and desktop ranked similarly in both environments. Focusing on listing ad experiences in terms of annoyance, a Bradley Terry logit model was used to establish a rank based on the number of times that an ad experience is more preferred than other. This method was used to establish the Initial Better Ads Standards, which indicates those ad formats that are discouraged to be used among the members of the Coalition. Although reports do not detail statistical analyses, results indicate the four worst ad experiences in desktop (see Table 2). Results in mobile differ slightly, and list a higher number of annoying ad experiences.

A third study was performed to validate results. Interestingly, to delimitate the line of what is an acceptable or unacceptable ad experiences, 607 participants were asked about more practical questions for the industry. That is, in addition to annoyance measures, users had to indicate if it was acceptable to show the ad on that web, their intentions to revisit and to recommend the webpage, and the worthiness of ad blocking installation. Overall, in a logical finding, the study concluded that those ads pointed out as bad practices in the second study are also those that increase the likelihood of ad blocking installation; and that this finding agrees with a couple of previous research. 
Table 2. Ad formats that are discouraged to be used according to the Initial Better Ads Standards

\begin{tabular}{|c|cc|}
\hline Desktop & \multicolumn{2}{|c|}{ Mobile } \\
\hline pop-up ads & pop-up ads & $\begin{array}{c}\text { poststitial ads that require a } \\
\text { countdown to dismiss } \\
\text { futo-playing videos with sound }\end{array}$ \\
prestitial ads with a countdown & $\begin{array}{c}\text { prestitial ads } \\
\text { fobile pages with more than } \\
\text { large sticky ads }\end{array}$ & $\begin{array}{c}\text { large sticky ads } \\
\text { flashing animations }\end{array}$ \\
\hline
\end{tabular}

However, despite the industry efforts to establish this objective standards, the research presents several limitations and weaknesses that are worth to notice. Determining which ad formats are allowed to continue, and which ones should gradually disappear is such a relevant decision that it needs to be carefully reviewed.

\section{Weaknesses of the Coalition's research}

Some of the clear weaknesses of the research are already presented in the studies as limitations. With the exception of some pilot interviews conducted in Germany, the core of the data was collected exclusively on the US, with no further geographical information about respondents. As far as culture, language or level of IT development strongly differ across countries, the standards should be based on a larger and broader sample of international users. As well, the studies only focus on desktop and mobile devices, ignoring ad experiences from other increasingly used devices such as tablets and smart TVs. Another limitation admitted by the Coalition is that experiments were based on a single context (i.e. reading an article from a publisher), whereas other context such as surfing online video could be also relevant to analyse.

Beyond manifested limitations, another set of important weaknesses need to be mentioned too. Surely, the most relevant flaw is that almost the complete research relies on MTurk. The troubles of relying on responses obtained from MTurk had been clearly identified by previous literature (e.g. Smith et al. 2016). In sum, the lack of control about respondents' information (who are they really?) and the presence of speeders and cheaters damage results' external validity, and limits the use of such data to provide meaningful managerial insights (Ford 2017).

The employed method also presents several weaknesses. The standards are based on users' responses about the most and least preferred ad format to be chosen among a set of three ad experiences. Sometimes each user has to repeat this procedure several times with different formats. That is, the experimental design forces users to evaluate each experience in a comparative and repetitive way. Users repeatedly exposed to the same ad assessing task become non-naïve about the actual purpose of the scenario, and would presumably focus on ads instead of engaging in a free navigation as a regular user would do. In other words, an interactive testing effect may occur because the previous measurement would be affecting participants' perception and responses to the experimental treatment (Dimitrov and Rumrill 2003). 
The Coalition's research presents other defects when reviewed from a scientific approach. The studies ignore any personal or situational elements influencing the assessment of the experience, especially for MTurk respondents (Ford 2017), such as familiarity with the publisher's website, time pressure, or users' involvement with the advertised product or the task. Practical aspects recently considered in online advertising literature, such as the level of congruency between the contents or formats of the ad and the context in which it is embedded are neither considered (Belanche, Flavián, and Pérez-Rueda 2017). Because of focusing exclusively on ad formats, the influence of creatives and consumer's involvement with the product is neglected too (Goodrich, Schiller, and Galletta 2015). In conclusion, the alliance research largely disregards previous scientific research on measures, methods or findings about users' avoidance of online advertising.

\section{Exploratory replication study}

\section{Method}

Two of the main weaknesses of the research conducted by the Coalition are relying on MTurk workers and conducting the research exclusively on the US. To overcome at least these limitations and as an additional contribution of this article, a basic exploratory study was conducted with a sample of 80 non-MTruk Spanish Internet users. Consistent with common research practices to perform online experiments (Bitter and Grabner-Kräuter 2016), participants were recruited by posting a link in social media. The research was described as a study about the content of an online website to be accessed by mobile phones with a duration between 5 and $10 \mathrm{~min}$. After clicking on the general link, participants were invited to read a text settled in a different website and come back to the study site to answer a few questions about it. To avoid bias derived from contextual factors, the same text and ads' content (i.e. brand, colour) used by the Coalition were replicated in this experiment. Nevertheless, because of the sample size limitation, the experiment focused only on the two ad formats ranked in the coalition as the highest (pop-up ad) and the lowest (sticky 320x50 ad on the top) in terms of users' annoyance ( $\mathrm{N}=40$ for each condition).

After reading the text in the web incorporating either the high annoyance ad (pop-up) or the low annoyance ad (sticky on the top), participants were invited to answer a questionnaire structured in four blocks. An initial block asked participants about their general perceptions and intentions towards the publisher website, using scales of perceived usefulness (from Bhattacherjee 2001), continuance intentions (Belanche et al. 2014) and WOM intentions (Ryu et al. 2012). The second block dealt with advertising effectiveness, and measured attitude toward the ad and direct questions of ad recall and brand recall to be assessed as a dummy right/wrong variable based on Belanche et al. (2017a, 2017b). The third block consisted of measures about users' experience toward the ad and included scales of advertising intrusiveness (McCoy et al. 2018), perceptions of goal impediment ( $\mathrm{Li}$ and Huang 2016), intention to install an ad blocker (based on Shiller et al. 2018), and their opinion about whether that kind of ad should "disappear", "be banned" and "forbidden" (own elaboration). With the exception of ad and brand recall, all the items in the measurement instrument were based on 7-point Likert scales. These scales provided Cronbach alpha values between 0.93 and 0.96 , above the 0.8 threshold recommended value (Nunnally 1978). The final section of the questionnaire requested some basic sociodemographic information of participants in terms of gender $(56.3 \%$ were female, $43.7 \%$ were male), age (55.0\% less than 25 years old, $18.7 \%$ between 25 and 35 years old, $10,0 \%$ between 35 and 50 , and $16.3 \%$ older than 50 years old), education level $(80.0 \%$ graduate or higher level), and occupation (47.5\% student, 34.2\% full time job, 8.5\% part time job, 9.8\% unemployed or retired). 


\section{Results and findings}

As an initial manipulation test, results confirmed that the high annoyance scenario presents a higher level of perceived intrusiveness than the low annoyance scenario $\left(\mathrm{M}_{\text {HighAnnoyance }}=4.06\right.$, $\left.\mathrm{M}_{\text {LowAnoyyance }}=2.06 ; t(79)=4.64, p<0.01\right)$.

Then, differences between the two scenarios were analysed in terms of the rest of variables. Results, depicted in Table 3, suggest that the damage of ad annoyance to the web of the publisher is minimal, as far as no significant differences between the two conditions were found for perceived website usefulness, continuance intention (i.e. loyalty), and WOM intention. Analyses on advertising effectiveness reveal an interesting finding also discussed in advertising literature (McCoy et al. 2008): presenting a high annoying ad harms user' attitude toward the ad but slightly increases the percentage of ad recall (non-significant difference). Finally, and in line with the Coalition research findings, results on perceptions about the online advertising experience suggest that users are fully aware of annoying advertising and committed to act against them. More precisely, users exposed to a highly annoying ad present higher levels of goal impediment perceptions, intentions to install ad blockers, and favourable opinion toward prohibiting that kind of ad, compared to users exposed to a lowly annoying ad.

\section{Discussion and future agenda}

The marketing legitimacy and relevance in the online market place, such as business models based on advertising, should not be questioned (Kitchen and Sheth 2016). In an unregulated digital world where the user is allegedly free to navigate, it seems that suffering advertising should be considered a quid pro quo exchange (Goldstein et al. 2014). Nevertheless, the absence of a formal or global regulation of advertising intrusiveness should not involve that extremely distracting, hyper-stimulating, long, or obtrusive ads would overpass some ethical limits. Using such intrusive ads not only damages consumer online experience, but is also negatively affecting publishers and advertising in the medium and long terms (Chatterjee 2008; McCoy et al. 2008).

This article aims to shed some light on an unexplored issue of ethics in advertising formats and specifically on the difficulty of determining standards in terms of intrusiveness or annoyance. From a conceptual approach, this article contributes to the advance of current approaches to digital advertising ethics by focusing on format intrusiveness. Based on the TARES test for ethical persuasiveness, this work explains why highly intrusive ads break many of the ethical limits of persuasive communication. From a practical approach, this research describes how the tremendous growth of ad blocker installation is shaking the advertising industry status quo, as an alarm of consumers' irritation against the use of intrusive advertising formats. In this sense, the Coalition for Better Ads represents an extraordinary opportunity to set deontological standards to be applied self-regulation; although it seems motivated more by practical (i.e. demotivates ad blocker installation) than ethical fundaments.

The Coalition for Better Ads deserves some merit for leading the challenging mission of putting order on unethical practices related to highly intrusive ad formats. First, the industry is seriously admitting that the existence of highly dissatisfying advertising experiences as well as the growth of a chaotic and harmful number of ad blocking systems. Second, the alliance is devoted to use objective consumer based research to establish ad format standards. Third, in the absence of a global internet government, the principal agents of the online advertising ecosystem have agreed to create a powerful alliance and are committed to expand the use of the standards by means of self-regulation. 
Table 3. Results of the exploratory replication study on two basic scenarios $(\mathrm{N}=\mathbf{8 0})$

\begin{tabular}{|c|c|c|c|c|}
\hline \multirow[b]{2}{*}{ Category } & \multirow[b]{2}{*}{ Variable } & \multicolumn{2}{|c|}{$\begin{array}{c}\text { Experimental } \\
\text { conditions }\end{array}$} & \multirow[b]{2}{*}{$t$-value } \\
\hline & & $\begin{array}{c}\text { Highly } \\
\text { annoying } \\
\text { ad } \\
\end{array}$ & $\begin{array}{c}\text { Lowly } \\
\text { annoying } \\
\text { ad } \\
\end{array}$ & \\
\hline \multirow{3}{*}{$\begin{array}{l}\text { Website related } \\
\text { perceptions and } \\
\text { intentions }\end{array}$} & Perceived usefulness & 2.73 & 2.93 & -0.51 \\
\hline & Continuance intention & 2.62 & 2.80 & -0.54 \\
\hline & WOM intention & 2.72 & 3.06 & -0.90 \\
\hline \multirow{3}{*}{ Ad effectiveness } & Attitude toward the ad & 2.01 & 2.58 & $-1.75^{*}$ \\
\hline & Ad recall ${ }^{\mathrm{a}}$ & 0.58 & 0.40 & NA \\
\hline & Brand recall ${ }^{\mathrm{a}}$ & 0.13 & 0.13 & NA \\
\hline \multirow{3}{*}{$\begin{array}{l}\text { Advertising } \\
\text { related } \\
\text { perceptions and } \\
\text { intentions }\end{array}$} & Goal impediment & 4.66 & 2.86 & $4.28 * * *$ \\
\hline & Intention to install an ad blocker & 4.76 & 3.46 & $2.42 * *$ \\
\hline & Opinion about prohibition & 4.38 & 2.52 & $3.85 * * *$ \\
\hline
\end{tabular}

Notes: $* p<0.10, * * p<0.05, * * * p<0.01$, NA not-applicable

a The percentages of ad and bran recall are expressed in fraction per unit, Pearson chi-square tests provide nonsignificant differences between conditions.

Nevertheless, a deep review of the Coalition's research to set Initial Best Standards reveals its numerous weaknesses and suggests that, before further advance, a broader validation and reflection about the experimental designs and their implications is required. Specifically, as far as these standards are going to be applied globally, studies would need to be replicated across countries, contexts, devices and ad contents. From a scientific approach, data collection procedure should be improved and would strongly benefit from regular respondents and more realistic experimental designs. In this sense, the Coalition is formed by companies with a privileged set of resources to develop field studies in order to test the actual consequences of using the standards in terms of ad blocking installation and many other relational consequences (e.g. ad effectiveness).

Results of the exploratory replication study presented in this article confirmed that highly annoying ads harm consumers' attitudes toward the ad and increase perceptions of goal impediment and intentions to install ad blockers. Consumers also have a positive opinion about prohibiting such kind of highly intrusive ad formats (i.e. pop-ups). In any case, this basic exploratory study is just an example to stimulate scholars to conduct further scientific research on advertising intrusiveness limits as a way to enhance or complement practitioners' approaches. 
A couple of remaining issues also deserve discussion. On the one hand, the continued appearance of increasingly intrusive ads in the online environment suggests that there is a need to place the consumer interest first as stated by research on consumer orientation and deontological ethics (Haefner 1991). Both ad blockers and the alliance claim that enhancing the users' experience is the main purpose of their actions. However, after decades of indifference about online advertising intrusiveness, these initiatives seem mere strategic actions in a highly competitive scenario between ad business models than an actual discussion about the ethical limits of using a highly dissatisfying consumer experience. The second idea is about advertising clutter in combination with the increasing lack of effectiveness (Ha and McCann 2008). From a managerial point of view, the focus on the advertising industry should not be only on eliminating those ad formats which result in higher levels of annoyance, but on making more effective ads that would contribute to reduce the too abundant number and kinds of online advertising. In line with previous empirical research (e.g. Goldstein et al. 2014), the study of advertising format appropriateness should be linked to intrusiveness but also to ad effectiveness (e.g. conversion rates, economical performance). Innovative formats (e.g. skippable ads) should be applied to simultaneously reduce ad intrusiveness and increase ad effectiveness.

Finally, there should be a call for a higher participation in such an important process of regulating the limits of advertising formats intrusiveness. Every initiative that aims to enhance users' experiences should more clearly involve consumers' opinion, for instance by integrating consumers' associations or giving them a higher participation in the establishment of standards. In addition, considering scholars' expertise on conducting high level scientific research on ad intrusiveness conceptualization and praxis (Riedel, Weeks, and Beatson 2018), advertising researchers should help practitioners in the mission of establishing such standards. It is a duty of all of us to further research, replicate and review all aspects concerning such a relevant and beneficial process for firms and consumers.

Acknowledgments: The author wishes to acknowledge the help provided by Lucia Fraile in the exploratory study.

Funding sources: Universidad de Zaragoza - Fundación Ibercaja (JIUZ-2017-SOC-05) and Antonio Gargallo Foundation (AEUPC-DB-2017).

\section{References}

Advertising Standards Authority. 2010. "The BCAP Code The UK Code of Broadcast Advertising” Accessed May 17, 2018. https://www.asa.org.uk/codes-andrulings/advertising-codes.html

Advertising Standards Authority. 2017. "Showing more impact. Committees of Advertising Practice. Annual Report 2017”. Accessed May 17, 2018. https://www.asa.org.uk/news/online-ads-overtake-tv-ads-for-complaints-with-double-thecases.html

Ady, R. W. (1967). "An investigation of the relationship between illuminated advertising signs and expressway accidents.” Traffic Safety Research Review 11 (3): 9-11.

Baker, S., and D. L. Martinson, D. L. 2001. "The TARES test: Five principles for ethical persuasion.” Journal of Mass Media Ethics 16 (2-3): 148-175. 
Belanche, D., C. Flavián, and A. Pérez-Rueda. 2017a. "Understanding interactive online advertising: congruence and product involvement in highly and lowly arousing, skippable video ads.” Journal of Interactive Marketing 37: 75-88.

Belanche, D., C. Flavián, and A. Pérez-Rueda. 2017b. "User adaptation to interactive advertising formats: The effect of previous exposure, habit and time urgency on ad skipping behaviors.” Telematics and Informatics 34 (7): 961-972.

Belanche, D., L. V. Casaló, C. Flavián, and J. Schepers. 2014. "Trust transfer in the continued usage of public e-services.” Information \& Management 51 (6): 627-640.

Beltramini, R. F. 2003. "Advertising ethics: the ultimate oxymoron?.” Journal of Business Ethics 48 (3): 215-216.

Bhattacherjee, A. 2001. "Understanding information systems continuance: an expectationconfirmation model.” MIS quarterly 25 (3): 351-370.

Bitter, S., and S. Grabner-Kräuter, S. 2016. "Consequences of customer engagement behavior: when negative Facebook posts have positive effects.” Electronic Markets 26 (3): 219-231.

Chatterjee, P. 2008. "Are unclicked ads wasted? Enduring effects of banner and pop-up ad exposures on brand memory and attitudes." Journal of Electronic Commerce Research 9 (1): 51-61.

Coalition for Better Ads. 2017. "Who We Are" Accessed November 24, 2017. https://www.betterads.org/about/

Cookson, R. 2015. "Google, Microsoft and Amazon pay to get around ad blocking tool" Financial Times. Accessed May 17, 2018. https://www.ft.com/content/80a8ce54-a61d11e4-9bd3-00144feab7de

Crundall, D., E. Van Loon, and G. Underwood. 2006. Attraction and distraction of attention with roadside advertisements. Accident Analysis \& Prevention 38 (4): 671-677.

Cunningham, P. 1999. “Ethics of advertising.” In J. P. Jones (Ed.), The advertising business, 499-513. London, UK: Sage.

Daems, K., P. De Pelsmacker, and I. Moons. 2018. "Advertisers' perceptions regarding the ethical appropriateness of new advertising formats aimed at minors." Journal of Marketing Communications, 1-19, in press.

Dimitrov, D. M., and P. D. Rumrill Jr. 2003. "Pretest-posttest designs and measurement of change.” Work 20 (2): 159-165.

Drumwright, M. E., and P. E. Murphy. 2009. “The current state of advertising ethics: Industry and academic perspectives.” Journal of Advertising 38 (1): 83-108.

Edwards, S. M., H. Li, and H. H. Lee. 2002. "Forced exposure and psychological reactance: Antecedents and consequences of the perceived intrusiveness of pop-up ads.” Journal of Advertising 31 (3): 83-95.

Feenstra, R. A., and E. González-Esteban. 2018. “Autocontrol: a critical study of achievements and challenges in the pursuit of ethical advertising through an advertising self-regulation system.” Journal of Business Ethics, 1-14, in press.

Ford, J. B. “Amazon's Mechanical Turk: A Comment.” Journal of Advertising, 46, 1 (2017): 156-158. 
Goldstein, D. G., S. Suri, R. P. McAfee, M. Ekstrand-Abueg, and F. Diaz. 2014. "The economic and cognitive costs of annoying display advertisements.” Journal of Marketing Research 51 (6): 742-752.

Goodrich, K., S. Z. Schiller, and D. Galletta. 2015. "Consumer reactions to intrusiveness of online-video advertisements.” Journal of Advertising Research 55 (1): 37-50.

Ha, L., and K. McCann. 2008. "An integrated model of advertising clutter in offline and online media.” International Journal of Advertising 27 (4): 569-592.

Haefner, M. J. 1991. "Ethical problems of advertising to children.” Journal of Mass Media Ethics 6 (2): 83-92.

James, E. L., C. B Pratt,. and T. V. Smith. 1994. "Advertising ethics: Practitioner and student perspectives. "Journal of Mass Media Ethics 9 (2): 69-83.

Keith, N. K., C. E. Pettijohn, and M. S. Burnett. 2003. “An empirical evaluation of the effect of peer and managerial ethical behaviors and the ethical predispositions of prospective advertising employees.” Journal of Business Ethics 48 (3): 251-265.

Kelly, L., G. Kerr, G., and J. Drennan. 2010. “Avoidance of advertising in social networking sites: The teenage perspective.” Journal of Interactive Advertising 10 (2): 16-27.

Key, W. B. 1973. Subliminal Seduction: Ad Media's Manipulation of A Not So Innocent America. Englewood Cliffs, NJ: Prentice-Hall..

Kitchen, P. J. 2017. "The complexities of online/offline communications." Journal of Marketing Communications 23 (2): 111-112.

Kitchen, P. J., J. N. Sheth. 2016. “Brickbats and bouquets for marketing.” European Journal of Marketing 50 (11): 1906-1923.

Li, H., S. M. Edwards, and J. H. Lee. 2002. "Measuring the intrusiveness of advertisements: Scale development and validation.” Journal of Advertising 31 (2): 37-47.

Li, W., and Z. Huang. 2016. "The research of influence factors of online behavioral advertising avoidance.” American Journal of Industrial and Business Management 6 (9): 947-957.

Lim, J. S., T. M. Chock, and G. J. Golan. 2018. "Consumer perceptions of online advertising of weight loss products: the role of social norms and perceived deception.” Journal of Marketing Communications, forthcoming.

McCoy, S., A. Everard, P. Polak, and D. F. Galletta. 2008. "An experimental study of antecedents and consequences of online ad intrusiveness." International Journal of Human-Computer Interaction 24 (7): 672-699.

Meader, A., L. Knight, R. Coleman, and L. Wilkins. 2015. "Ethics in the digital age: A comparison of the effects of moving images and photographs on moral judgment.” Journal of Media Ethics 30 (4): 234-251.

Moore, T. E. 1982. "Subliminal advertising: What you see is what you get." The Journal of Marketing 46 (2): 38-47.

Moraes, C., and N. Michaelidou. 2017. "Introduction to the special thematic symposium on the ethics of controversial online advertising.” Journal of Business Ethics 141 (2): 231-233.

Nunnally, J. C. (1978). Psychometric theory ( $2^{\text {nd }}$ ed.). New York: McGraw-Hill.

Page Fair. 2017. "The state of the blocked web. Global Adblock Report”. Accessed May 17, 2018. https://pagefair.com/blog/2017/adblockreport/ 
Redondo, I. and G. Aznar. 2018. "To use or not to use ad blockers? The roles of knowledge of ad blockers and attitude toward online advertising." Telematics and Informatics, forthcoming.

Riedel, A. S., C. S. Weeks, and A. T. Beatson. 2018. "Am I intruding? Developing a conceptualisation of advertising intrusiveness." Journal of Marketing Management, forthcoming.

Rinallo, D., S. Basuroy, R. Wu, and H. J. Jeon. 2013. "The media and their advertisers: exploring ethical dilemmas in product coverage decisions.” Journal of Business Ethics 114 (3): 425-441.

Robin, D. P., and R. E. Reidenbach. 1987. "Social responsibility, ethics, and marketing strategy: Closing the gap between concept and application.” The Journal of Marketing 44-58.

Sabri, O. 2017. "Does viral communication context increase the harmfulness of controversial taboo advertising?.” Journal of Business Ethics 141 (2): 235-247.

Shaver, D. 2003. "Toward an analytical structure for evaluating the ethical content of decisions by advertising professionals.” Journal of Business Ethics 48 (3): 291-300.

Shiller, B., J. Waldfogel, and J. Ryan. 2018. "The effect of ad blocking on website traffic and quality.” RAND Journal of Economics 49 (1): 43-63.

Smith, S. M., C. A. Roster, L. L. Golden, and G. S. Albaum. 2016. “A multi-group analysis of online survey respondent data quality: comparing a regular USA consumer panel to MTurk samples.” Journal of Business Research 69 (8): 3139-3148.

Spencer, S. 2017. "How we fought bad ads, sites and scammers in 2016”. Accessed September 21, 2018. https://www.blog.google/technology/ads/how-we-fought-bad-ads-sites-andscammers-2016/

Tudoran A. A. 2018. "Why do Internet consumers block ads? New evidence from consumer opinion mining and sentiment analysis.” Internet Research, Forthcoming.

Van Doorn, J., and J. C. Hoekstra. 2013. "Customization of online advertising: The role of intrusiveness.” Marketing Letters 24 (4): 339-351.

Villarán, A. 2017. "Irrational advertising and moral autonomy.” Journal of Business Ethics 144 (3): 479-490.

Volkov, M., D. Harker, and M. Harker. 2002. “Opinions about advertising in Australia: a study of complainants.” Journal of Marketing Communications 8 (4): 229-242. 